Disclaimer: This is preliminary scientific work that has not been peer reviewed. We share it here to inform other scientists conducting research on this topic, but the reported findings should not be used as a basis for policy or practice.

Parent-for-child Mask Wearing Behavior during the COVID-19 Pandemic: An Investigation of Attitudes, Beliefs and Norms using the Theory of Planned Behavior

Adina Coroiu ${ }^{1 *}$, Chelsea Moran ${ }^{2 *}$, Brittany L. Lindsay ${ }^{2}$ \& Alan C. Geller ${ }^{1}$

${ }^{1}$ Department of Social and Behavioral Sciences, Harvard T.H. Chan School of Public Health, Boston, Massachusetts, USA

${ }^{2}$ Department of Psychology, University of Calgary, Calgary, Alberta, Canada

*Shared first authorship

Corresponding author:

Adina Coroiu, PhD, Research Fellow, Harvard T.H. Chan School of Public Health

401 Park Drive, West Wing 4th floor, 403G, Boston MA, 02215

Email: acoroiu@hsph.harvard.edu

\title{
Table/Figure count:
}

3 Tables

1 Figure

2 Supplementary Materials (Supplementary Table S1 and Table S2) 


\section{Funding}

This study did not receive any funding. AC is supported by post-doctoral research fellowships from the Canadian Institutes of Health Research (CIHR) and Fonds de Recherche du Quebec - Santé (FRQS). CM is supported by doctoral awards from Vanier Canada, Killam Trusts, and Alberta Innovates, and a Training in Research and Clinical Trials in Integrative Oncology (TRACTION) fellowship from the University of Calgary. BL is supported by a Social Sciences and Humanities Research Council (SSHRC) doctoral scholarship.

\section{Conflict of interests}

None declared.

\section{Author's contribution}

AC, CM, AG: conceptualization, design

$\mathrm{AC}, \mathrm{CM}, \mathrm{BL}$ : data analysis

BL: statistical consultation

$A C, C M$ : first draft

All authors read and approved the final manuscript.

\section{Data availability}

Data can be downloaded from the Open Science Framework: https://osf.io/y5xg9/ 


\section{Abstract}

Background: Mask continue to be a necessity until a large proportion of the population, including children, receive immunizations for COVID-19. The aim of this study was to investigate the relationship between parental attitudes and beliefs about masks and parent-for-child mask behavior using the Theory of Planned Behavior.

Method: We administered a survey in August 2020 to parents of school-aged children residing in the United States and Canada. Measures included sociodemographic variables for the parent and child, attitudes, norms and perceived control over children's mask use, and enforcement of mask wearing among children (also titled "parent-for-child mask behavior"). Data were anlyzed using structural equation modelling.

Results: We collected data from 866 parents and $43.5 \%$ had children with pre-existing health conditions (e.g., allergies, anxiety, impulsivity, skin sensitivity, asthma) that made extended mask wearing difficult. Among the full sample, negative attitudes $(\beta=-.20, p=.006)$, norms $(\beta=.41, p=.002)$, and perceived control $(\beta=.33, p=$ .006) predicted intentions. Norms $(\beta=.50, p=.004)$ and intentions $(\beta=.28, p=.003)$ also predicted parent-forchild mask use, while attitudes and perceived control did not. Intentions mediated the associations between the predictors (attitudes, norms, perceived control) and outcome (mask behavior). Subgroup analyses revelaved intentions as the key predictor of parent-for-child mask use among children with pre-conditions and norms as the key predictor among children without pre-conditions.

Conclusion: Future public health messaging should target parental intentions, attitudes and beliefs about masks wearing among children.

Word count: $245(\max 250)$

Keywords: COVID-19, mask use, protective behaviours, parent-for-child behaviour, theory of planned behavior 


\section{Background}

Mask wearing is the most accepted and accessible strategy to mitigate transmission of the virus that causes COVID-19 [1], even after vaccination. Despite aggressive COVID-19 vaccination campaigns for teachers in the United States, transmission can still occur in schools. For example, surveillance data from the state of Massachusetts collected from 18 district dashboards in seven counties from 9/1/20 through 2/27/21 shows that community transmission rates among children (3,199 cases in 67,157 children) are similar to those found at the community level (28,303 cases in 556,000 adults) at $5 \%$ (Personal Communication). This suggests that children can act as vectors for the disease, unlike previously speculated [2]. Absent a COVID-19 vaccine with demonstrated efficacy and safety among children, schools continue to face unprecedented challenges to contain transmission, many of which are dependent on the availability of resources to implement preventive measures [3] and parents willingness' to adhere to and enforce public health recommendations among their children.

Masks are effective at preventing transmission of the SARS-Cov-2 virus among adults as well as children. For example, a 2020 meta-analysis found that face masks were associated with a decreased risk of infection of respiratory viruses, including SARS-CoV-2 [4]. A large population study conducted in the US found that compared to states with mask mandates implemented within 1 month, the states without mask mandates or with masks implemented later had higher infection rates [1]. Mask use has also been shown to reduce transmission among children. A cross-sectional study conducted in the US with individuals 13 year of age and older $(\mathrm{N}=378,207)$ found that wearing face masks was associated with reduced community transmission of COVID-19, as measured by the instantaneous reproductive number $\left(\mathrm{R}_{\mathrm{t}}\right)$ [5]. A cross-sectional survey conducted in Canada with parents of school-aged children $(\mathrm{N}=565)$ found that increased mask wearing and fewer attended gatherings were associated with lower seropositivity among children aged 8 to 13 years; and for each attended gathering, children wearing masks had a 9.7 increased likelihood of being seropositive compared to 1.02 odds in children not wearing a mask [6]. 
Specific interventions that have been implemented in schools during the COVID-19 pandemic include organizational policies to make contacts safe (e.g., face mask, hand hygiene, physical distancing policies, alternating attendance); environmental measures (e.g., improved ventilation, school yard division, distance between desks); and surveillance approaches (e.g., testing, tracing, symptom screening, isolation, and quarantine) [3]. Institutional policies are only effective when used consistently, and resources to implement more costly measures vary across schools. Masks are arguably a low-cost, high-impact strategy to mitigate transmission of SARS-Cov-2 among children both within and outside of school settings. Mask use is mandated in indoor settings, which would include schools, in many jurisdictions in the US [7] and Canada [8], yet children spend a good proportion of their time engaged in activities where health policy enforcement might not be readily available, e.g., during sports and leisure activities, recess, play dates, on route to and from school. In such instances, where there is less systematic oversight, wearing masks might be the only reliable strategy to prevent COVID-19 transmission when physical distancing is not possible. For example, a large survey conducted in the US with students aged 13-21, who attended school in person in 2020, found the percentage of students reporting wearing masks "all the time" was highest in classrooms, hallways, and stairwells (65\%) compared to school buses (42\%), restrooms (40\%), and cafeterias (36\%) with even lower rates reported during sports and extracurricular activities (28\%) or while outside on school property (25\%) [9]. Another study showed that among US individuals 13 years and older, 85\% were "likely to wear a mask at grocery store", while only $40 \%$ were "likely to wear a mask while visiting with family/friends at home" and $40 \%$ were "very likely to wear a mask to the grocery store and when visiting with family/friends" [5]. A cross-sectional survey conducted in Wuhan, China with children aged 6-13 ( $\mathrm{N}=8569)$ found an increased likelihood of wearing a mask in school among grades 5 and 6 compared to grades 1 and 2, whereby roughly over half of all children reported "good mask behavior," as per health guidelines recommendations [10]. Lastly, a cross-sectional survey conducted in the US prior to school openings with parents/ guardians of school-aged children $(N=2202)$ found that parental support for mandatory mask mandates in schools varied as a function of child's grade ( $36.4 \%$ supported masks in kindergarten; $40.2 \%$ in grades $1-2 ; 48.0 \%$ in grades $3-5 ; 52.2 \%$ in grade $>=6)$. [11]. 
Pending mass vaccination campaigns for school-aged children, masks remain a key strategy for COVID19 prevention. With children spending equal amounts of time within controlled school settings and outside of these settings, it is important to determine the individual-level factors that would promote compliance to mask use during activities without direct institutional or parental oversight. Parental attitudes, beliefs, and behaviors in support of children's health behaviours have been shown to have a direct effect in children's adoption and enactment of such behaviours, a process termed "parent-for-child" behavior [12].

\section{Conceptual Model and Study Objective}

As parents of school-aged children are key decision makers about in-person school attendance and mask wearing in schools, there is a strong need to identify parental attitudes, beliefs, and behaviors about children's mask wearing in schools. The Theory of Planned Behavior (TPB) [13] is a social-psychological theory designed to explain antecedents to behavioral intention and action, with a focus on attitudes (i.e., benefits and consequences of performing or not performing the behavior), subjective norms (i.e., desire to meet expectations of others regarding the behavior) and perceived control (i.e., personal capacity to perform the behavior and costs/constraints). A 2020 meta-analysis ( $\mathrm{N}=46$ studies) investigating determinants of parent-forchild behaviors using the TPB model found that attitudes, norms and perceived control predicted parental enforcement of health behavior in children and these relationships were mediated by intentions [14]. Notably, an empirical study testing the TPB in parent-adolescent dyads found a bi-directional influence of the model tenets (attitudes, norms, perceived control, and intentions) on parent-to-adolescent behavior and adolescentto-parent behavior [15]. Few studies have used the TPB model to predict COVID-19 preventive behaviors, including social and physical distancing among general population samples in Bangladesh [16] and Hong Kong [17] and intentions to wear masks among international students [18]. To our knowledge, there are no studies that applied the TPB model to predict parent-for-child COVID-19 protective behaviors, such as mask wearing.

This study aimed to identify modifiable determinants of parent-for-child mask behavior. Specifically, we investigated parental attitudes, beliefs, intentions, and modelling behaviours for children's mask wearing. We used the Theory of Planned Behavior [13] to guide the selection of theoretical predictors for our two 
outcomes, intentions and behaviour, and conducted structural equation modelling to identify the strongest predictors. Our findings can inform public health messaging about mask wearing within and outside school settings throughout the ongoing process of immunization against COVID-19.

\section{Methods}

\section{Study Design}

This study used a cross-sectional survey design. Recruitment and data collection were conducted online using the Qualtrics platform. The Institutional Research Board of the Harvard TH Chan School of Public Health granted ethics approval for the study. The reporting of the study followed the STROBE guideline [19] (see Supplementary Materials Table S1). The data is freely accessible at https://osf.io/y5xg9/.

\section{Participants and Procedures}

The study was advertised online via a paid Facebook advertisement (\$100 CAD/day) targeting individuals residing in Canada and the US. Data collection was conducted between July 30, 2020 and August 10, 2020. Eligibility for this study included being an adult (18 years or older), a parent/caregiver of a school-aged child and living in Canada or the US. Survey completion took $11.7+/-10.1$ minutes. The survey can be found at https://osf.io/y5xg9/.

Predictor Variables

Sociodemographic information. Participants were asked to indicate their age, gender, ethnicity, country of residence, highest level of education completed, household income, work and health status, family size, self-perceived symptoms of COVID-19 over the previous week, and whether they were tested for COVID19; and the demographic status of their youngest school-aged child, including age, gender, overall health status, and specific health conditions (e.g., allergies, anxiety).

Attitudes about children's mask wearing in schools. Attitudes were assessed via three separate items ("I worry that wearing face masks in school could lead to disruptions in my child's daily activities", "I worry that wearing face masks in school could lead to negative interactions with peers and teachers for my child", and "I worry that wearing face masks in school could lead to my child having difficulty reading social cues"), which 
were scored on a 5-point Likert-type scale, ranging from 1 (not at all concerned) to 5 (very concerned). Higher scores indicated more negative attitudes. In the current sample, Cronbach's alpha was .95.

Subjective norms about mask wearing among children. Norms about mask wearing were assessed via three items (e.g., "Masks should be worn all the time when in public and physical distancing is not possible", "I believe that when used properly, face masks are effective at preventing transmission of the virus that causes COVID-19", and "I believe the benefits of wearing face masks when in public outweigh the potential concerns") which were scored on a 5-point Likert-type scale, ranging from 1 (strongly disagree) to 5 (strongly agree). Higher scores indicated increased acceptance of common norms about mask wearing. In the current sample, Cronbach's alpha was .95 .

Perceived control over mask wearing by children. Perceived control or self-efficacy for teaching children how to wear masks was assessed via three items (e.g., "I am confident I can teach my child how to wear and adjust a face mask", "I will be able to provide my child with a face mask to wear to school every day", and "I am confident I can explain to my child the benefits of wearing a face mask") which were scored on a 5point Likert-type scale, ranging from 1 (strongly disagree) to 5 (strongly agree). Higher scores indicated greater perceived control. In the current sample, Cronbach's alpha was .89.

\section{Outcome Variables}

Intentions to have children wear masks in schools. Intentions to have children wear masks in schools were assessed via a single item ("I intend to have my child wear a face mask at school") which was assessed on a 5-point Likert-type scale, ranging from 1 (strongly disagree) to 5 (strongly agree). Higher scores indicated higher intentions.

Parent-for Child Mask behavior. To assess children's mask behavior in schools we used a single item ("When I take my child out in public, I insist they wear a face mask") which was assessed on a 5-point Likerttype scale, ranging from 1 (none of the time) to 5 (all of the time), with an additional option available for those not leaving their homes ( $6=1$ don't go out). Higher scores indicated more frequent mask use among children. 
We opted to use this item to approximate children's mask wearing behaviour in schools, because at the time of data collection, schools were not yet open, so the question could not be asked retrospectively.

\section{Data Analysis Plan}

Descriptive statistics (mean, standard deviation, percentages) were conducted in SPSS version 27. Structural equation modelling (SEM) analyses with ML bootstrapping with 500 iterations and $95 \%$ confidence intervals ( $\mathrm{Cl}$ ) were conducted in AMOS version 25 [20] to test the TPB model (See Figure 1). As part of SEM analysis, we conducted a series of confirmatory factor analyses for each of the multi-item constructs (i.e., attitudes, subjective norms, and perceived control). We used factor loadings and Cronbach's alpha to evaluate the internal consistency of the scales.

For the main analysis, we concurrently estimated 1) the associations between attitudes, subjective norms, perceived control, and intentions, 2) the direct effects of attitudes, subjective norms, perceived control, and intentions on mask behavior, and 3) the indirect effects of attitudes, subjective norms, and perceived control on mask behavior through intentions. A priori, we identified parental education level and health status, child's age and health status, and country of residence (Canada versus US), as covariates for the model. Upon inspection of the associations between the proposed covariates and the outcomes, we excluded country of residence from final model, as it was not associated with either one of the outcomes [21,22].

To assess model fit, we used the chi-square test, which is highly sensitive to sample size and potentially leading to erroneous rejection of the model fit [23], in tandem with a combination of other indices, i.e., the Tucker-Lewis Index [TLI; 24], the Comparative Fit Index [CFI; 25] and the Root Mean Square Error of Approximation [RMSEA; 26]. Good fitting models are indicated by a TLI and CFI $\geq .95$ and RMSEA $\leq .06$ [27], although a CFI and TLI of .90 or above [28] and a RMSEA of .08 or less [29] are regarded as indicators of an adequate model fit. Standardized regression coefficients were used to assess the strength of individual paths included in the model. The magnitude of the associations (expressed via standardized regression coefficients or $\beta)$ was interpreted following Cohen's effect size descriptors, i.e., $S D \leq .20$ indicating small, $\leq .50$ indicating moderate, and $\leq .80$ indicating large effect sizes [30]. 
Post-hoc Multi-Group Analyses. We conducted multiple-group analyses testing the TPB model among parents of children with pre-existing health conditions versus parents of children without pre-existing conditions (referred to as pre-conditions hereafter). This decision was based on preliminary descriptive analyses that showed that approximately $50 \%$ of our participants had children with at least one pre-condition. To determine whether the measurement model (i.e., item loadings onto latent predictors) was similar across the two groups, we conducted an invariance analysis with the three latent variables (attitudes, norms, perceived control). This analysis evaluates differences between the model fit of an unconstrained model (i.e., one that allows all parameters to vary by subgroup) and two constrained models (i.e., assumes certain parameters to be equal between subgroups): the measurement weights model (i.e., paths from latent variables to measured items constrained) and the structural covariances model (i.e., correlations between latent variables). A significantly poorer model fit (determined by a significant chi square difference test) for the constrained model(s) compared to the unconstrained model is indicative of differences in the parameters that are constrained across the two subgroups. After this, we inspected the model fit indices and the path coefficients of the full SEM model by group. Lastly, after observing noticeable differences in path coefficients from all variables to mask behavior between the two subgroups, we conducted subsequent post-hoc z-tests to evaluate significant differences between the two subgroups, with a Bonferroni corrected significance level for these tests [31].

\section{Results}

\section{Recruitment and Sample characteristics}

Data were collected from 869 participants but 170 participants who completed fewer than $50 \%$ of the survey and/or had missing values for any variables used in the model were excluded. Therefore, analyses were conducted with 699 participants with non-missing data on all variables tested in the model. Among the total sample, $94.7 \%$ were females (mothers) with a mean age of $44.4(+/-8.4)$ years old, $84.0 \%$ had completed college or university, and $83.7 \%$ were married or in a common-law relationship. A total of $54.1 \%$ of parents reported having a female youngest child of school age and $43.5 \%$ reported their child having a pre-existing 
condition that might interfere with mask wearing. The most frequently reported pre-conditions included allergies (20.9\%), anxiety (20.7\%), impulsivity (19.7\%), skin sensitivity (16.3\%), and asthma (12.7\%). Parent-for child mask behaviour and self-reported parental mask use in public were correlated at $r=.86, p<.001$.

Demographic sample characteristics are included in Table 1.

\section{Predictors of Parent-for-Child Mask Behavior Using the Theory of Planned Behaviour}

Descriptive statistics for the study measures are included in Table 2. Results of the SEM analysis are included in Table 3. The model fit was acceptable for the analysis conducted across the full sample. Additional model fit indices provided by the software but not included in the model fit evaluation are included in Supplementary Table S2.

Negative attitudes $(\beta=-.20, p=.006)$, norms $(\beta=.41, p=.002)$, and perceived control $(\beta=.33, p=$ .006) were significantly associated with intentions. The magnitude of these associations was "small" for attitudes and "moderate" for norms and perceived control. We found "moderate" direct effects of norms $(\beta=$ $.50, p=.004)$ and intentions $(\beta=.28, p=.003)$ on mask behavior. There was no direct effect of attitudes or perceived control on mask behavior. We also found "small" indirect effects (i.e., mediated by intentions), of attitudes $(\beta=-.06, p=.003)$, norms $(\beta=-.11, p=.001)$, and perceived control $(\beta=-.09, p=.002)$ on mask behavior.

\section{Subgroup Analyses among Parents of Children Without and With Pre-existing Conditions}

Measurement invariance. Using the unconstrained model as a baseline model, there was no significant difference between the unconstrained model and the measurement weights model, $\chi^{2}(6)=4.75, p=.576$, indicating no difference in item loadings across groups (see Table 2 for item loadings). There was a significant difference in model fit when comparing the unconstrained model to the structural covariances model, $\chi^{2}(12)=$ $21.12, p=.049$, indicating that the correlations between the three predictors might differ by group. Using a Bonferroni corrected significance level ( $\alpha=.017$; three z-tests), the correlation between attitudes and norms was significantly higher in the group without pre-conditions $(r=.84)$ compared to the group with preconditions $(r=.78, z=2.24, p=.012)$. The correlations between attitudes and control $\left(r_{\text {none }}=.86 ; r_{\text {pre-cond }}=.77\right.$; 
$z=1.747, p=.040)$ and between norms and control $\left(r_{\text {none }}=.88 ; r_{\text {pre-cond }}=.88 ; z=1.645, p=.050\right)$ were not statistically different between the two groups. Aside from slightly stronger correlations in one group than the other, the measurement models were similar. The model fit indices were comparable across both groups (see Table 3).

Detailed subgroup analyses are included in Table 3. Among parents of children without pre-conditions $(n=304)$, attitudes, norms and perceived control were significantly associated with intentions; attitudes and norms had a direct effect on mask behavior but perceived control and intentions did not; and there were no indirect effects (i.e., through intentions) on mask behavior. Among parents of children with pre-conditions $(\mathrm{n}=$ 395), attitudes, norms and perceived control were significantly associated with intentions; intentions and norms had a direct effect on mask behavior but attitudes and perceived control did not; attitudes, norms, and perceived control also had a "small" indirect effect (i.e., through intentions) on mask behavior. Post-hoc pairwise comparisons of path coefficients using a Bonferroni corrected $\alpha=.013$ found that the path from norms to mask behavior was significantly stronger in the group without pre-conditions $(\beta=.72, p=.006)$ compared to the group with pre-conditions $(\beta=.28, p=.019), z=-2.99, p=.001$.

\section{Discussion}

"Let me just state for the record that masks are not theater. Masks are protective" [32]. With immunization campaigns for adults underway, recommendations remain in place to continue to use masks while indoors and in public spaces where social distancing is not possible $[33,34]$. This is particularly relevant to children residing in the US for whom vaccines will likely become available in late 2021 or beyond [35], with Canada likely to follow a similar vaccination schedule.

In the current study we used a theoretical model of health behavior change, i.e., the Theory of Planned Behavior (TPB) [13] and robust statistical analyses, i.e., structural equation modelling, to estimate predictors of parent-for-child mask wearing behavior. We surveyed parents of school-aged children across US and Canada, half of whom reported having a child with at least one pre-condition that could hypothetically interfere with mask wearing. Frequently reported pre-conditions included allergies, anxiety, and impulsivity. We found that 
attitudes about masks, beliefs about mask effectiveness (or norms), and beliefs about being able to teach and model adequate mask wearing behavior to children (or perceived control) were associated with parents' intentions to have children wear masks. Norms and intentions were also associated with parental enforcement of mask wearing among children (or parent-for-child mask behavior) but attitudes and perceived control were not. Lastly the individual relationships between attitudes, norms, perceived control, respectively, and mask behavior were mediated by intentions. This suggests that while holding positive attitudes about mask wearing, positive beliefs about mask effectiveness, and having a sense of efficacy over how to teach children to wear masks are important constructs, ultimately their relationship to parent-for-child mask behavior is heavily influenced by parents' intentions to have children wear masks.

Subgroup analyses of parents with children with pre-conditions that affect mask wearing and parents of children without pre-conditions showed a more nuanced view of the main results. It appears that for parents of children without pre-conditions (i.e., healthy children) norms or holding positive beliefs about mask effectiveness have the largest impact on parent-for-child mask use, as there are arguably fewer foreseeable barriers to mask use. Conversely, for parents of children with pre-conditions, intentions are the main drivers of parent-for-child mask use: enforcing mask use among children with pre-cnditions is a more complex and challenging process, which involves the need for intentional planning, in addition to attitudes, norms and perceived control.

Previous studies, which applied the Theory of Planned Behavior Model to predict preventive behaviours during the COVID-19 pandemic, found that attitudes, perceived control and social norms were associated with increased mask wearing among international students enrolled at Chinese universities [18]; positive attitudes (but not negative), perceived control and social norms were associated with increased social and physical distancing behaviours among general population adults living in Hong Kong [17]. A third study found that intentions mediated the relationship between attitudes and social distancing behavior and perceived control and behavior, respectively, among an adult general population sample recruited from Bangladesh [16]. Similar to the current project, previous studies used cross-sectional designs and convenience 
samples primarily recruited on social media. Our study adds to this small body of literature by providing a viewpoint on parents' approach to children's mask wearing, most importantly about the mediative role of intention in the link between attitudes, norms, perceived control, and parent-for-child mask wearing.

Previous studies have shown that parents of school-aged children have concerns about potential harms of mask wearing to the health and socio-emotional development of children (e.g., masks potentially preventing adequate communication in the classroom, blocking emotional signaling between teachers and children) [36]. Parental concerns about children's mask use may be magnified among parents of children with pre-existing health conditions [37]. In the current study, roughly half of the parents had children with pre-conditions that interfered with mask use. However, given the large number of parents with children with pre-conditions in our study (44\%), we were able to conduct subgroup analyses and uncovered different pathways predicting mask wearing among the two subsets of parents.

\section{Limitations}

First, this study used a cross sectional design which limits our ability to make longitudinal predictions. Although we hypothesized the relationships between our variables using the Theory of Planned Behavior and modelled our paths using structural equation modelling, with our design it was not possible to test causal relationships between the variables, as one would with a longitudinal design. Second, we used a convenience sample, composed primarily of women, which included a high percentage of parents of children with preconditions reported by parents as potentially interfering with mask wearing. The characteristics of our sample might limits the generalizability our results. Third, we collected these data in August 2020 prior to the beginning of the 2020 fall semester, when vaccines were not available for adults and there was no foreseeable plan for vaccine trials in children. Despite the time lag between data collection and publication, our results are applicable to the current climate, given the ongoing need to wear masks in public. Last, we assessed our constructs with items created ad-hoc for this study, as there were no COVID-19 specific measures available at the time we started data collection. Real-time rates of children's mask wearing in schools could not be measured in this study, as schools had not been opened at the time of data collection. 
Future Directions

Future research should cross-validate these findings in studies conducted with more diverse samples, particularly individuals from marginalized groups, people of color, and those financially disadvantaged, as well as using real-life mask behaviors of children in schools as the model outcome. The challenge remains on how to improve children's mask wearing while not directly supervised by parents or when supervised by teachers in classroom settings. Children spend a lot of time unsupervised with many not wearing masks consistently while in school and neither closely supervised nor reminded to do so by adults. This suggests that interventions are needed to boost parental attitudes, beliefs, and behaviors relative to masks, such as those assessed herein, which could act as motivators (or drivers) for children's mask wearing in multiple settings, not just those in the classroom. Moreover, we suggest that mask-wearing has to be more of a societal, collective decision made by parents so that children's mask wearing is not limited only to classroom situations.

\section{Conclusions/Implications}

Our key finding is that parents' intentions to have children wear masks is am important mediator of the association between beliefs about negative consequences of masks (attitudes), beliefs about mask effectiveness (norms), confidence in modelling adequate mask wearing to children (perceived control), and parent-for-child mask use. Public health messaging around children's mask wearing should target parents' misconceptions about negative consequences of wearing masks (e.g., by delivering accurate information about mask effectiveness, addressing common myths about masks via story telling of personal accounts, providing easily digestible scientific evidence about mask usefulness, and transparent communication of known/unknown risks), and tap parents' internal motivations to have children wear masks (e.g., to protect self and others, to protect community, to protect those who are vulnerable) [38]. Lessons learned from this study about the importance of intention to parental enforcement of wearing mask could be extended to other other COVID-19 protective behaviours among children, such as COVID-19 vaccine uptake. 
References

1. Krishnamachari B, Morris A, Zastrow D, Dsida A, Harper B, Santella AJ. The role of mask mandates, stay at home orders and school closure in curbing the COVID-19 pandemic prior to vaccination. American journal of infection control. 2021:S0196-6553(0121)00057-00052.

2. Vogel L. Have we misjudged the role of children in spreading COVID-19? Canadian Medical Association Journal. 2020;192(38):E1102.

3. Krishnaratne S, Pfadenhauer LM, Coenen M, et al. Measures implemented in the school setting to contain the COVID-19 pandemic: a rapid scoping review. Cochrane Database of Systematic Reviews. 2020(12).

4. Chu DK, Akl EA, Duda S, et al. Physical distancing, face masks, and eye protection to prevent person-toperson transmission of SARS-CoV-2 and COVID-19: a systematic review and meta-analysis. The Lancet. 2020;395(10242):1973-1987.

5. Rader B, White LF, Burns MR, et al. Mask-wearing and control of SARS-CoV-2 transmission in the USA: a cross-sectional study. The Lancet Digital Health. 2021;3(3):e148-e157.

6. Manny E, Carroll A, Charlton C, et al. Increased Mask Use and Fewer Gatherings Associated with Lower SARS-CoV-2 Seropositivity Among Young School-Age Children [Pre-Print]. SSRN. 2020.

7. Guzman-Cottrill JA, Malani AN, Weber DJ, et al. Local, state and federal face mask mandates during the COVID-19 pandemic. Infection control and hospital epidemiology. 2021;42(4):455-456.

8. Government of Canada. COVID-19 guidance for schools Kindergarten to Grade 12. https://www.canada.ca/en/public-health/services/diseases/2019-novel-coronavirus-infection/healthprofessionals/guidance-schools-childcare-programs.html. Published 2021. Accessed April 21, 2021.

9. Arvelo W, Fahrenbruch M, Hast M, Puddy R. COVID-19 Stats: Percentage of Middle and High School Students Aged 13-21 Years Attending In-Person Classes Who Reported Observing Fellow Students Wearing a Mask All the Time, ${ }^{*}$ by School Setting and Activity-United States, October 2020. Morbidity and Mortality Weekly Report. 2021;70(6):223. 
10. Chen X, Ran L, Liu Q, Hu Q, Du X, Tan X. Hand Hygiene, Mask-Wearing Behaviors and Its Associated Factors during the COVID-19 Epidemic: A Cross-Sectional Study among Primary School Students in Wuhan, China. Int J Environ Res Public Health. 2020;17(8).

11. Chua KP, DeJonckheere M, Reeves SL, Tribble AC, Prosser LA. Factors Associated With School Attendance Plans and Support for COVID-19 Risk Mitigation Measures Among Parents and Guardians. Acad Pediatr. 2020.

12. Hagger MS, Hamilton K. Health Behavior, Health Promotion, and the Transition to Parenthood: Insights from Research in Health Psychology and Behavior Change. In: Taubman - Ben-Ari O, ed. Pathways and Barriers to Parenthood: Existential Concerns Regarding Fertility, Pregnancy, and Early Parenthood. Cham: Springer International Publishing; 2019:251-269.

13. Ajzen I. From Intentions to Actions: A Theory of Planned Behavior. In: Kuhl J, Beckmann J, eds. Action Control: From Cognition to Behavior. Berlin, Heidelberg: Springer Berlin Heidelberg; 1985:11-39.

14. Hamilton K, van Dongen A, Hagger MS. An extended theory of planned behavior for parent-for-child health behaviors: A meta-analysis. Health Psychology. 2020;39(10):863.

15. Joyal-Desmarais K, Lenne RL, Panos ME, et al. Interpersonal effects of parents and adolescents on each other's health behaviours: a dyadic extension of the theory of planned behaviour. Psychology \& Health. 2019;34(5):569-589.

16. Das AK, Abdul Kader Jilani MM, Uddin MS, Uddin MA, Ghosh AK. Fighting ahead: Adoption of social distancing in COVID-19 outbreak through the lens of theory of planned behavior. Journal of Human Behavior in the Social Environment. 2021:1-21.

17. Yu Y, Lau JTF, Lau MMC. Levels and factors of social and physical distancing based on the Theory of Planned Behavior during the COVID-19 pandemic among Chinese adults. Translational behavioral medicine. 2021:ibaa146.

18. Sun Y, Qin B, Hu Z, et al. Predicting mask-wearing behavior intention among international students during COVID-19 based on the theory of planned behavior. Annals of palliative medicine. 2021. 
19. von Elm E, Altman DG, Egger M, Pocock SJ, Gøtzsche PC, Vandenbroucke JP. The Strengthening the Reporting of Observational Studies in Epidemiology (STROBE) Statement: guidelines for reporting observational studies. Int J Surg. 2014;12(12):1495-1499.

20. $\quad \operatorname{Amos}($ Version 25.0, SPSS) [computer program]. Chicago, IL: IBM; 2017.

21. Becker TE. Potential Problems in the Statistical Control of Variables in Organizational Research: A Qualitative Analysis With Recommendations. Organizational Research Methods. 2005;8(3):274-289.

22. Spector PE, Brannick MT. Methodological Urban Legends: The Misuse of Statistical Control Variables. Organizational Research Methods. 2011;14(2):287-305.

23. Reise SP, Widaman KF, Pugh RH. Confirmatory factor analysis and item response theory: Two approaches for exploring measurement invariance. Psychological Bulletin. 1993;114(3):552-566.

24. Tucker LR, Lewis C. A reliability coefficient for maximum likelihood factor analysis. Psychometrika. 1973;38:1-10.

25. Bentler PM. Comparative fit indexes in structural models. Psychological Bulletin. 1990;107(2):238-246.

26. Steiger JH. Structural model evaluation and modification: An interval estimation approach. Multivariate Behavioral Research. 1990;25(2):173-180.

27. Hu L, Bentler PM. Cutoff criteria for fit indexes in covariance structure analysis: Conventional criteria versus new alternatives. Structural Equation Modeling: A Multidisciplinary Journal. 1999;6(1):1-55.

28. Kline RB. Principles and practice of structural equation modeling 2nd Ed. ed. New York: Guilford Press; 2005.

29. Browne MW, Cudeck R. Alternative ways of assessing fit. In: Bollen KA, Long JS, eds. Testing structural equation models. Newbury Park: Sage; 1993:136-162.

30. Cohen J. Statistical power analysis for the behavioral sciences 2nd Ed. ed. Hillsdale, NJ Lawrence Erlbaum Associates; 1988.

31. Meyers LS, Gamst G, Guarino AJ. Applied multivariate research: Design and interpretation. Sage publications; 2016. 
32. Fauci A. Dr. Fauci Testimony Speech Transcript March 18: "Masks Are Not Theatre".

https://www.rev.com/blog/transcripts/dr-fauci-testimony-speech-transcript-march-18-masks-are-nottheatre. Published 2021. Accessed April 21, 2021.

33. Center for Disease Control and Prevention. Use Masks to Slow the Spread of COVID-19. https://www.cdc.gov/coronavirus/2019-ncov/prevent-getting-sick/diy-cloth-face-coverings.html. Published 2021. Accessed March 24, 2021.

34. Government of Canada. Coronavirus disease (COVID-19): Prevention and risks. https://www.canada.ca/en/public-health/services/diseases/2019-novel-coronavirusinfection/prevention-risks.html\#p. Published 2021. Accessed March 24, 2021.

35. White House COVID-19 Task Force, Dr. Fauci Press Conference Transcript April 2 [press release]. April 21, 20212021.

36. Spitzer M. Masked education? The benefits and burdens of wearing face masks in schools during the current Corona pandemic. Trends in neuroscience and education. 2020;20:100138-100138.

37. Esposito S, Principi N, Leung CC, Migliori GB. Universal use of face masks for success against COVID-19: evidence and implications for prevention policies. European Respiratory Journal. 2020:2001260.

38. Coroiu A, Moran C, Campbell T, Geller AC. Barriers and facilitators of adherence to social distancing recommendations during COVID-19 among a large international sample of adults. PLOS ONE. 2020;15(10):e0239795. 
Table 1. Sample Characteristics

\begin{tabular}{|c|c|c|c|}
\hline Variable & $\begin{array}{l}\text { Full sample } \\
\qquad(N=699)\end{array}$ & $\begin{array}{c}\text { Children without } \\
\text { pre-conditions } \\
(\mathrm{N}=304)\end{array}$ & $\begin{array}{c}\text { Children with } \\
\text { pre-conditions } \\
(\mathrm{N}=395) \\
\end{array}$ \\
\hline \multicolumn{4}{|l|}{ PARENTS } \\
\hline \multicolumn{4}{|l|}{ Country, $n(\%)$} \\
\hline USA & $341(48.8)$ & $164(53.9)$ & $177(44.8)$ \\
\hline Canada & $358(51.2)$ & $140(46.1)$ & $218(55.2)$ \\
\hline Age, M (SD) & $44.39(8.41)$ & $44.45(8.31)$ & $44.34(8.50)$ \\
\hline \multicolumn{4}{|l|}{ Gender, $n(\%)$} \\
\hline Male & $28(4.0)$ & $15(4.9)$ & $13(3.3)$ \\
\hline Female & $662(94.7)$ & $283(93.1)$ & 379 (95.9) \\
\hline Non-binary & $6(0.8)$ & $4(1.3)$ & $2(0.5)$ \\
\hline Other & $1(0.1)$ & $0(0.0)$ & $1(0.3)$ \\
\hline Missing & $2(0.3)$ & $2(0.7)$ & $0(0.0)$ \\
\hline \multicolumn{4}{|l|}{ Education, $n(\%)$} \\
\hline Highschool & $85(12.2)$ & $30(9.9)$ & $55(13.9)$ \\
\hline Trade school & 27 (3.9) & $8(2.6)$ & $19(4.8)$ \\
\hline College & $229(32.8)$ & $100(32.9)$ & $129(32.7)$ \\
\hline University & $358(51.2)$ & $166(54.6)$ & $192(48.6)$ \\
\hline \multicolumn{4}{|l|}{ Marital status, $n(\%)$} \\
\hline Single & $47(6.7)$ & $17(5.6)$ & $30(7.6)$ \\
\hline In a relationship or common-law & $58(8.3)$ & $21(6.9)$ & $37(9.4)$ \\
\hline Married & $527(75.4)$ & $245(80.6)$ & $282(71.4)$ \\
\hline Separated/divorced & $52(7.4)$ & $17(5.6)$ & $35(8.9)$ \\
\hline Widowed & 13 (1.9) & $3(1.0)$ & $10(2.5)$ \\
\hline Missing & $2(0.3)$ & $1(0.3)$ & $1(0.3)$ \\
\hline \multicolumn{4}{|l|}{ Household income, $n(\%)$} \\
\hline$<\$ 44,999$ & $100(15.1)$ & $33(10.9)$ & $67(17.0)$ \\
\hline $45,000-\$ 49,999$ & $26(3.7)$ & $7(2.3)$ & $19(4.8)$ \\
\hline$\$ 50,000-\$ 54,999$ & $31(4.4)$ & $9(3.0)$ & $22(5.6)$ \\
\hline$\$ 55,000-\$ 59,999$ & $17(2.4)$ & $7(2.3)$ & $10(2.5)$ \\
\hline$\$ 60,00-\$ 64,999$ & $30(4.3)$ & $16(5.3)$ & $14(3.5)$ \\
\hline$\$ 65,000-\$ 69,999$ & $17(2.6)$ & $9(3.0)$ & $8(2.0)$ \\
\hline$\$ 70,000-\$ 74,999$ & $36(5.2)$ & $12(3.9)$ & $24(6.1)$ \\
\hline$\$ 75,000-\$ 79,999$ & $39(5.6)$ & $18(5.9)$ & $21(5.3)$ \\
\hline$>\$ 80,000$ & $366(52.4)$ & $170(55.9)$ & $196(49.6)$ \\
\hline Missing & $37(5.3)$ & $23(7.6)$ & $14(3.5)$ \\
\hline \multicolumn{4}{|l|}{ Ethnicity, $n(\%)^{*}$} \\
\hline Asian & $14(2.0)$ & $8(2.6)$ & $6(1.5)$ \\
\hline Black or African American & $3(0.4)$ & $3(1.0)$ & $0(0.0)$ \\
\hline Hispanic & $25(3.6)$ & $7(2.3)$ & $18(4.6)$ \\
\hline Indigenous/Alaskan Native & $16(2.3)$ & $5(1.6)$ & $11(2.8)$ \\
\hline Middle Eastern or North African & $6(0.9)$ & $2(0.7)$ & $4(1.0)$ \\
\hline Pacific Islander & $2(0.2)$ & $1(0.3)$ & $1(0.3)$ \\
\hline White & $636(91.0)$ & $295(97.0)$ & $359(90.9)$ \\
\hline Missing & $26(3.7)$ & $11(3.6)$ & $15(3.8)$ \\
\hline \multicolumn{4}{|l|}{ Self-reported health status, $n(\%)$} \\
\hline Poor & $11(1.6)$ & $1(0.3)$ & $10(2.5)$ \\
\hline
\end{tabular}




\begin{tabular}{|c|c|c|c|}
\hline Variable & $\begin{array}{l}\text { Full sample } \\
\qquad(N=699)\end{array}$ & $\begin{array}{l}\text { Children without } \\
\text { pre-conditions } \\
(\mathrm{N}=304)\end{array}$ & $\begin{array}{c}\text { Children with } \\
\text { pre-conditions } \\
(\mathrm{N}=395) \\
\end{array}$ \\
\hline Fair & $81(11.6)$ & $17(5.6)$ & $64(16.2)$ \\
\hline Good & $236(33.8)$ & $93(30.6)$ & $143(36.2)$ \\
\hline Very good & $236(33.8)$ & $107(35.2)$ & $129(32.7)$ \\
\hline Excellent & $135(19.3)$ & $86(28.3)$ & $49(12.4)$ \\
\hline \multicolumn{4}{|l|}{ YOUNGEST CHILD } \\
\hline Age, M (SD) & $9.43(3.80)$ & $9.19(3.75)$ & $9.63(3.83)$ \\
\hline \multicolumn{4}{|l|}{ Gender, $n(\%)$} \\
\hline Male & $317(45.4)$ & $136(44.7)$ & $181(45.8)$ \\
\hline Female & $378(54.1)$ & $166(54.6)$ & $212(53.7)$ \\
\hline Non-binary & $2(0.3)$ & $1(0.3)$ & $1(0.3)$ \\
\hline Missing & $2(0.3)$ & $1(0.3)$ & $1(0.3)$ \\
\hline \multicolumn{4}{|l|}{ Type of school, $n(\%)$} \\
\hline Public school & $591(84.5)$ & $253(83.2)$ & $338(85.6)$ \\
\hline Private school & $76(10.9)$ & $40(13.2)$ & $36(9.1)$ \\
\hline Homeschool & $4(0.6)$ & $2(0.7)$ & $2(0.4)$ \\
\hline Missing & $29(4.0)$ & $9(3.0)$ & $19(4.8)$ \\
\hline \multicolumn{4}{|l|}{ Parent-reported health status, $n$ (\%) } \\
\hline Poor & $1(0.1)$ & $0(0.0)$ & $1(0.3)$ \\
\hline Fair & $31(4.4)$ & $1(0.3)$ & $30(7.6)$ \\
\hline Good & $131(18.7)$ & $28(9.2)$ & $103(26.1)$ \\
\hline Very good & $238(34.0)$ & $92(30.3)$ & $146(37.0)$ \\
\hline Excellent & $298(42.6)$ & $183(60.2)$ & $115(29.1)$ \\
\hline \multicolumn{4}{|l|}{ Pre-existing conditions, $n(\%)^{*}$} \\
\hline Allergies & $146(20.9)$ & - & $146(20.9)$ \\
\hline Anxiety & $145(20.7)$ & - & $145(20.7)$ \\
\hline Impulsivity & $138(19.7)$ & - & $138(19.7)$ \\
\hline Skin Sensitivity & $114(16.3)$ & - & $114(16.3)$ \\
\hline Asthma & $89(12.7)$ & - & $89(12.7)$ \\
\hline Body Image & $35(5.0)$ & - & $35(5.0)$ \\
\hline Difficulty Breathing & $29(4.1)$ & - & $29(4.1)$ \\
\hline $\begin{array}{l}\text { Difficulty reading facial } \\
\text { expressions }\end{array}$ & $29(4.1)$ & - & $29(4.1)$ \\
\hline Hearing difficulties & $20(2.9)$ & - & $20(2.9)$ \\
\hline Difficulty recognizing others & $9(1.3)$ & - & $9(1.3)$ \\
\hline Immunity disorder & $9(1.3)$ & - & $9(1.3)$ \\
\hline Mobility Issues & $8(1.1)$ & - & $8(1.1)$ \\
\hline Autism & $8(1.1)$ & - & $8(1.1)$ \\
\hline Difficulty reading lips & $7(1.0)$ & - & $7(1.0)$ \\
\hline Speech Learning Disorder & $7(1.0)$ & - & $7(1.0)$ \\
\hline Neuro Special Needs & $6(0.9)$ & - & $6(0.9)$ \\
\hline Depression & $2(0.3)$ & - & $2(0.3)$ \\
\hline
\end{tabular}

Note. ${ }^{*}$ Percentages do not equal $100 \%$ because the question asked participants to check all options that apply. 
Table 2. Descriptive Statistics for the Study Measures

\begin{tabular}{|c|c|c|c|c|c|c|c|c|c|c|}
\hline \multirow{2}{*}{\multicolumn{2}{|c|}{ Variable }} & \multicolumn{3}{|c|}{$\begin{array}{l}\text { Full sample } \\
(\mathrm{N}=699)\end{array}$} & \multicolumn{3}{|c|}{$\begin{array}{l}\text { Children without pre-conditions } \\
\qquad(\mathrm{N}=304)\end{array}$} & \multicolumn{3}{|c|}{$\begin{array}{l}\text { Children with pre-conditions } \\
\qquad(\mathrm{N}=395)\end{array}$} \\
\hline & & $M(S D)$ & $\begin{array}{l}\text { Factor } \\
\text { loading }\end{array}$ & $95 \% \mathrm{Cl}$ & $M(S D)$ & $\begin{array}{l}\text { Factor } \\
\text { loading }\end{array}$ & $95 \% \mathrm{Cl}$ & $M(S D)$ & $\begin{array}{l}\text { Factor } \\
\text { loading }\end{array}$ & $95 \% \mathrm{Cl}$ \\
\hline \multicolumn{11}{|c|}{ Attitudes $^{\mathrm{a}}$} \\
\hline 1) & $\begin{array}{l}\text { I worry that wearing face masks in school could lead to disruptions } \\
\text { in my child's daily activities. }\end{array}$ & $2.75(1.59)$ & .93 & $.91, .95$ & $2.88(1.64)$ & .94 & $.91, .96$ & $2.65(1.54)$ & .92 & $.90, .94$ \\
\hline 2) & $\begin{array}{l}\text { I worry that wearing face masks in school could lead to negative } \\
\text { interactions with peers and teachers for my child. }\end{array}$ & $2.61(1.63)$ & .95 & $.93, .96$ & $2.76(1.65)$ & .97 & $.94, .98$ & $2.49(1.60)$ & .94 & $.91, .96$ \\
\hline 3) & $\begin{array}{l}\text { I worry that wearing face masks in school could lead to my child } \\
\text { having difficulty reading social cues. }\end{array}$ & $2.81(1.52)$ & .90 & $.88, .92$ & $2.92(1.56)$ & .93 & $.91, .95$ & $2.73(1.48)$ & .88 & $.83, .90$ \\
\hline \multicolumn{11}{|c|}{ Subjective norms ${ }^{\mathrm{b}}$} \\
\hline 4) & $\begin{array}{l}\text { Masks should be worn all the time when in public and physical } \\
\text { distancing is not possible. }\end{array}$ & $3.64(1.58)$ & .94 & $.92, .96$ & $3.32(1.68)$ & .95 & $.93, .97$ & $3.89(1.47)$ & .93 & $.89, .95$ \\
\hline 5) & $\begin{array}{l}\text { I believe that when used properly, face masks are effective at } \\
\text { preventing transmission of the virus that causes COVID-19. }\end{array}$ & $3.49(1.41)$ & .89 & $.86, .91$ & $3.23(1.48)$ & .90 & $.85, .93$ & $3.69(1.32)$ & .88 & $.83, .91$ \\
\hline 6) & $\begin{array}{l}\text { I believe the benefits of wearing face masks when in public } \\
\text { outweight the potential concerns. }\end{array}$ & $3.59(1.57)$ & .95 & $.93, .97$ & $3.34(1.68)$ & .96 & $.92, .98$ & $3.77(1.45)$ & .95 & $.93, .97$ \\
\hline \multicolumn{11}{|c|}{ Perceived control ${ }^{b}$} \\
\hline 7) & $\begin{array}{l}\text { I will be able to provide my child with a face mask to wear to school } \\
\text { every day. }\end{array}$ & $3.99(1.29)$ & .79 & $.74, .84$ & $3.79(1.34)$ & .78 & $.71, .84$ & $4.14(1.23)$ & .79 & $.71, .84$ \\
\hline 8) & $\begin{array}{l}\text { I am confident I can teach my child how to wear and adjust a face } \\
\text { mask. }\end{array}$ & $3.78(1.31)$ & .84 & $.81, .87$ & $3.63(1.34)$ & .87 & $.83, .91$ & $3.89(1.27)$ & .82 & $.75, .87$ \\
\hline 9) & $\begin{array}{l}\text { I am confident I can explain to my child the benefits of wearing a } \\
\text { face mask. }\end{array}$ & $3.76(1.45)$ & .93 & $.91, .95$ & $3.48(1.55)$ & .95 & $.92, .97$ & $3.98(1.33)$ & .92 & $.88, .95$ \\
\hline \multicolumn{11}{|c|}{ Intentions } \\
\hline \multirow{2}{*}{\multicolumn{11}{|c|}{ Mask Behavior }} \\
\hline & & & & & & & & & & \\
\hline 11) & When I take my child out in public, I insist they wear a face mask. ${ }^{c}$ & $3.46(1.58)$ & & & $3.23(1.65)$ & & & $3.64(1.51)$ & & \\
\hline
\end{tabular}

Note. $\mathrm{M}=$ mean; $\mathrm{SD}=$ standard deviation; $\mathrm{Cl}=$ confidence intervals for factor loadings, bootstrapped.

${ }^{a}$ Measured with five-point Likert scale ranging from 1 (not at all) to 5 (very worried)

${ }^{\mathrm{b}}$ Measured with five-point Likert scale ranging from 1 (strongly disagree) to 5 (strongly agree)

${ }^{\mathrm{c}}$ Measured with a five-point Likert scale ranging from 1 (none of the time) to 5 (all of the time). 
Table 3. Predictors of Parental Intentions to Have Children Wear Masks in Schools and Mask Wearing Behavior

\begin{tabular}{|c|c|c|c|c|c|c|c|c|c|}
\hline \multirow[t]{2}{*}{ Variable } & \multicolumn{3}{|c|}{$\begin{array}{l}\text { Full sample } \\
\qquad(\mathrm{N}=699)\end{array}$} & \multicolumn{3}{|c|}{$\begin{array}{l}\text { Children without } \\
\text { pre-conditions } \\
(\mathrm{N}=304)\end{array}$} & \multicolumn{3}{|c|}{$\begin{array}{l}\text { Children with } \\
\text { pre-conditions } \\
(\mathrm{N}=395)\end{array}$} \\
\hline & $\beta$ & $95 \% \mathrm{Cl}$ & $\mathrm{p}$ & $\beta$ & $95 \% \mathrm{Cl}$ & $\mathrm{p}$ & $\beta$ & $95 \% \mathrm{Cl}$ & $\mathrm{p}$ \\
\hline \multicolumn{10}{|l|}{ Predictors of Intentions } \\
\hline Attitudes & -.20 & $-.29,-.11$ & .006 & -.23 & $-.38,-.09$ & .005 & -.19 & $-.30,-.07$ & .012 \\
\hline Norms & .41 & $.26, .57$ & .002 & .40 & $.17, .60$ & .003 & .42 & $.19, .65$ & .007 \\
\hline Perceived control & .33 & $.17, .49$ & .006 & .31 & $.11, .55$ & .003 & .34 & $.06, .56$ & .015 \\
\hline \multicolumn{10}{|c|}{ Direct Effects on Mask Behavior } \\
\hline Attitudes & -.07 & $-.21, .08$ & .398 & -.19 & $-.40,-.01$ & .035 & .01 & $-.20, .18$ & .970 \\
\hline Norms & .50 & $.32, .68$ & .004 & .72 & $.45, .97$ & .006 & .28 & $.06, .54$ & .019 \\
\hline Perceived control & -.03 & $-.22, .16$ & .711 & -.20 & $-.49, .04$ & .095 & .12 & $-.15, .38$ & .348 \\
\hline Intentions & .28 & $.14, .42$ & .003 & .14 & $-.05, .33$ & .194 & .39 & $.21, .56$ & .003 \\
\hline \multicolumn{10}{|c|}{ Indirect Effects on Mask Behavior } \\
\hline Attitudes & -.06 & $-.10,-.02$ & .003 & -.04 & $-.12, .00$ & .053 & -.08 & $-.15,-.03$ & .006 \\
\hline Norms & .11 & $.06, .19$ & .001 & .07 & $.00, .18$ & .042 & .17 & $.07, .31$ & .004 \\
\hline Perceived control & .09 & $.04, .17$ & .002 & .06 & $-.00, .16$ & .055 & .13 & $.03, .25$ & .016 \\
\hline \multicolumn{10}{|l|}{ Overall Model Fit Indices } \\
\hline$X^{2}(D F), p$ & & $305.01(61)$ & $<.001$ & & $168.32(61)$ & $<.001$ & & $227.26(61)$ & $<.001$ \\
\hline $\mathrm{CFI}$ & & .97 & & & .98 & & & .96 & \\
\hline TLI & & .95 & & & .96 & & & .94 & \\
\hline RMSEA & & .08 & & & .08 & & & .08 & \\
\hline
\end{tabular}

Note. $\mathrm{X}^{2}$ = Chi-squared statistic; DF = degrees of freedom; CFI = Comparative Fit Index; TLI = Tucker Lewis Index; RMSEA = Root Mean Square

Error of Approximation. Direct effects = associations between the 3 predictors and the outcome, controlling for parent's education level,

parent's health status, child's age, and child's health status. Indirect effects = association between the 3 predictors and outcome through Intentions. 


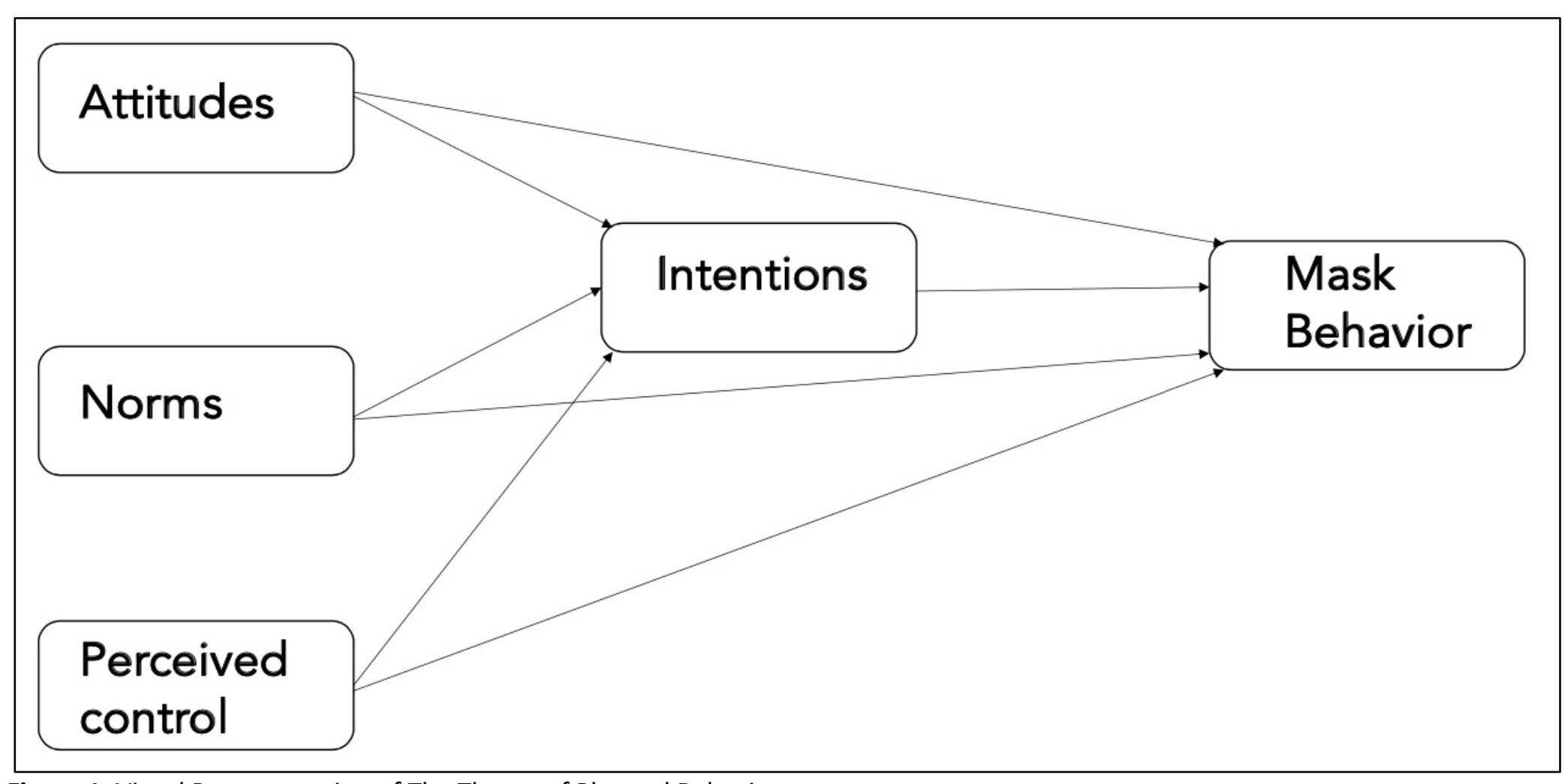

Figure 1. Visual Representation of The Theory of Planned Behavior

Note. Attitudes ( 3 items) e.g., "I worry that wearing face masks in school could lead to disruptions in my child's daily activities".

Norms ( 3 items) e.g., "Masks should be worn all the time when in public and physical distancing is not possible".

Perceived control ( 3 items) e.g., "I am confident I can teach my child how to wear and adjust a face mask".

Intentions (1 item): "I intend to have my child wear a face mask at school".

Mask Behavior (1 item): "When I take my child out in public, I insist they wear a face mask". 


\section{Supplementary Materials}

Supplementary Table S1. STROBE Statement-Checklist of items that should be included in reports of cross-sectional studies

\begin{tabular}{|c|c|c|c|}
\hline & $\begin{array}{l}\text { Item } \\
\text { No }\end{array}$ & Recommendation & Page Number \\
\hline \multirow[t]{2}{*}{ Title and abstract } & \multirow[t]{2}{*}{1} & (a) Indicate the study's design with a commonly used term in the title or the abstract & $1-2$ \\
\hline & & $\begin{array}{l}\text { (b) Provide in the abstract an informative and balanced summary of what was done } \\
\text { and what was found }\end{array}$ & 2 \\
\hline \multicolumn{4}{|l|}{ Introduction } \\
\hline Background/rationale & 2 & Explain the scientific background and rationale for the investigation being reported & $4-7$ \\
\hline Objectives & 3 & State specific objectives, including any prespecified hypotheses & $6-7$ \\
\hline \multicolumn{4}{|l|}{ Methods } \\
\hline Study design & 4 & Present key elements of study design early in the paper & 7 \\
\hline Setting & 5 & $\begin{array}{l}\text { Describe the setting, locations, and relevant dates, including periods of recruitment, } \\
\text { exposure, follow-up, and data collection }\end{array}$ & 7 \\
\hline Participants & 6 & $\begin{array}{l}\text { (a) Give the eligibility criteria, and the sources and methods of selection of } \\
\text { participants }\end{array}$ & 7 \\
\hline Variables & 7 & $\begin{array}{l}\text { Clearly define all outcomes, exposures, predictors, potential confounders, and effect } \\
\text { modifiers. Give diagnostic criteria, if applicable }\end{array}$ & 7-9 \\
\hline $\begin{array}{l}\text { Data sources/ } \\
\text { measurement }\end{array}$ & $8^{*}$ & $\begin{array}{l}\text { For each variable of interest, give sources of data and details of methods of } \\
\text { assessment (measurement). Describe comparability of assessment methods if there is } \\
\text { more than one group }\end{array}$ & 7-9 \\
\hline Bias & 9 & Describe any efforts to address potential sources of bias & N/A \\
\hline Study size & 10 & Explain how the study size was arrived at & $\begin{array}{l}\text { N/A - descriptive study, no a priori } \\
\text { power analysis }\end{array}$ \\
\hline $\begin{array}{l}\text { Quantitative } \\
\text { variables }\end{array}$ & 11 & $\begin{array}{l}\text { Explain how quantitative variables were handled in the analyses. If applicable, } \\
\text { describe which groupings were chosen and why }\end{array}$ & $9-10$ \\
\hline \multirow[t]{5}{*}{ Statistical methods } & \multirow[t]{5}{*}{12} & (a) Describe all statistical methods, including those used to control for confounding & $9-10$ \\
\hline & & (b) Describe any methods used to examine subgroups and interactions & $9-10$ \\
\hline & & (c) Explain how missing data were addressed & 10 \\
\hline & & (d) If applicable, describe analytical methods taking account of sampling strategy & N/A \\
\hline & & (e) Describe any sensitivity analyses & N/A \\
\hline
\end{tabular}

Results 

$\begin{array}{ll}\text { Participants } & 13^{*} \\ \text { (a) Report numbers of individuals at each stage of study-eg numbers potentially } \\ \text { eligible, examined for eligibility, confirmed eligible, included in the study, completing }\end{array}$ follow-up, and analysed

(b) Give reasons for non-participation at each stage

$10-11$

(c) Consider use of a flow diagram

N/A - Information not collected

(a) Give characteristics of study participants (eg demographic, clinical, social) and

Tables 1 and 2

\begin{tabular}{|c|c|c|c|}
\hline \multirow[t]{2}{*}{ Descriptive data } & \multirow[t]{2}{*}{$14^{*}$} & $\begin{array}{l}\text { (a) Give characteristics of study participants (eg demographic, clinical, social) and } \\
\text { information on exposures and potential confounders }\end{array}$ & 10-11, Tables 1 and 2 \\
\hline & & (b) Indicate number of participants with missing data for each variable of interest & 10 \\
\hline Outcome data & $15^{*}$ & Report numbers of outcome events or summary measures & N/A \\
\hline \multirow[t]{3}{*}{ Main results } & \multirow[t]{3}{*}{16} & $\begin{array}{l}\text { (a) Give unadjusted estimates and, if applicable, confounder-adjusted estimates and } \\
\text { their precision (eg, 95\% confidence interval). Make clear which confounders were } \\
\text { adjusted for and why they were included }\end{array}$ & $\begin{array}{l}\text { 11-12, Tables } 3 \text {, Supplementary } \\
\text { Table } 1\end{array}$ \\
\hline & & (b) Report category boundaries when continuous variables were categorized & N/A \\
\hline & & $\begin{array}{l}\text { (c) If relevant, consider translating estimates of relative risk into absolute risk for a } \\
\text { meaningful time period }\end{array}$ & N/A \\
\hline Other analyses & 17 & $\begin{array}{l}\text { Report other analyses done-eg analyses of subgroups and interactions, and } \\
\text { sensitivity analyses }\end{array}$ & $11-12$ \\
\hline \multicolumn{4}{|l|}{ Discussion } \\
\hline Key results & 18 & Summarise key results with reference to study objectives & $12-13$ \\
\hline Limitations & 19 & $\begin{array}{l}\text { Discuss limitations of the study, taking into account sources of potential bias or } \\
\text { imprecision. Discuss both direction and magnitude of any potential bias }\end{array}$ & 14 \\
\hline Interpretation & 20 & $\begin{array}{l}\text { Give a cautious overall interpretation of results considering objectives, limitations, } \\
\text { multiplicity of analyses, results from similar studies, and other relevant evidence }\end{array}$ & $12-15$ \\
\hline Generalisability & 21 & Discuss the generalisability (external validity) of the study results & 14 \\
\hline \multicolumn{4}{|c|}{ Other information } \\
\hline Funding & 22 & $\begin{array}{l}\text { Give the source of funding and the role of the funders for the present study and, if } \\
\text { applicable, for the original study on which the present article is based }\end{array}$ & 2 \\
\hline
\end{tabular}

*Give information separately for exposed and unexposed groups.

Note: An Explanation and Elaboration article discusses each checklist item and gives methodological background and published examples of transparent reporting. The STROBE checklist is best used in conjunction with this article (freely available on the Web sites of PLoS Medicine at

http://www.plosmedicine.org/, Annals of Internal Medicine at http://www.annals.org/, and Epidemiology at http://www.epidem.com/). Information on the

STROBE Initiative is available at www.strobe-statement.org. 
Supplementary Table S2. Model Fit Indices

\begin{tabular}{|c|c|c|c|c|}
\hline Indices & Cut-offs & $\begin{array}{l}\text { Full sample } \\
\text { ( } N=699)\end{array}$ & $\begin{array}{l}\text { Children without } \\
\text { pre-conditions } \\
(\mathrm{N}=304)\end{array}$ & $\begin{array}{c}\text { Children with pre- } \\
\text { conditions } \\
(\mathrm{N}=395)\end{array}$ \\
\hline \multicolumn{5}{|l|}{ Absolute } \\
\hline$X^{2}(D F)$ & & $305.01(61)$ & $168.32(61)$ & $227.26(61)$ \\
\hline $\mathrm{p}$ & & $<.001$ & $<.001$ & $<.001$ \\
\hline & $>.95$ good & & & \\
\hline GFI & >.90 acceptable & 0.95 & .94 & .93 \\
\hline RMSEA & $\begin{array}{l}<.06 \text { good } \\
<.08 \text { acceptable }\end{array}$ & .08 & .08 & .08 \\
\hline \multicolumn{5}{|l|}{ Relative } \\
\hline CFI & & .97 & .98 & .97 \\
\hline $\mathrm{NFI}$ & $>.95$ good & .97 & .96 & .95 \\
\hline IFI & $>.90$ acceptable & .97 & .98 & .97 \\
\hline TLI & & .95 & .96 & .94 \\
\hline \multicolumn{5}{|l|}{ Parsimonious } \\
\hline PGFI & $>.50$ & .48 & .47 & .47 \\
\hline PNFI & $>.50$ & .56 & .56 & .55 \\
\hline Overall model fit & & Acceptable & Acceptable & Acceptable \\
\hline
\end{tabular}

